\title{
Animais Domésticos e o Risco de Transmissão de Agentes Patogênicos para a Fauna Silvestre na Área de Entorno do Parque Nacional da Tijuca
}

\author{
Gabriela Heliodoro ${ }^{1}$, Carlos Eduardo Verona ${ }^{2} \&$ Henrique Rajão ${ }^{3}$
}

Recebido em 21/10/2019 - Aceito em 22/06/2020

1 Instituto de Pesquisas Jardim Botânico do Rio de Janeiro/JBRJ, Equipe de Conservação da Fauna do Jardim Botânico do Rio de Janeiro/ FAUNA/JBRJ, Rio de Janeiro/RJ, Brasil. CEP: 22.460-000. <gabiheli@gmail.com>.

2 Instituto Brasileiro para Medicina da Conservação/Tríade, Recife/PE, Brasil. CEP: 51.021-530. Zoológico do Rio de Janeiro S/A/RioZoo, Gerência Técnica, Rio de Janeiro/RJ, Brasil. CEP: 20.940-040. <carloseduardoverona@gmail.com>.

3 Pontifícia Universidade Católica do Rio de Janeiro/PUC-Rio, Centro de Ciências Biológicas e da Saúde, Departamento de Biologia, Rio de Janeiro/RJ, Brasil. CEP: 22.451-900. <henrique.rajao@gmail.com>.

\begin{abstract}
RESUMO - Animais domésticos são potencialmente portadores de agentes patogênicos de risco para a fauna silvestre, constituindo-se uma ameaça constante em áreas urbanas, como o Parque Nacional da Tijuca (PNT) e sua zona de amortecimento, onde vivem em grande número nas comunidades do entorno. Assim como o PNT, o Jardim Botânico do Rio de Janeiro (JBRJ) sofre pressão da urbanização, abrigando, na fronteira com o PNT, uma comunidade conhecida como Horto $(\mathrm{CH})$, situação que aproxima fauna silvestre, animais domésticos e homem. É imprescindível conhecer as características de saúde, manutenção e manejo de animais domésticos no entorno das unidades de conservação para planejar ações de proteção à fauna silvestre, pois agentes etiológicos podem devastar populações silvestres ou estas servirem de amplificadoras dos agentes, diminuindo a eficiência de ações de controle da saúde pública. O objetivo principal deste estudo é identificar a presença potencial de agentes infecciosos de risco para a fauna silvestre, na área do JBRJ e entorno, situada na zona de amortecimento do PNT. Para tal, utilizamos questionários tendo como informantes moradores da $\mathrm{CH}$ e veterinários da região, além de dados da Equipe de Conservação da Fauna do JBRJ, que serviram de apoio para as análises. Os animais da comunidade não se encontram representados nos registros de atendimentos nas clínicas da região, havendo animais não vacinados $e$ negligenciados, principalmente entre gatos. Consideramos que existe risco para a fauna nativa em diversos níveis, e risco de reemergência de raiva felina, principalmente. A partir dos resultados obtidos, foi possível compreender características e crenças locais, o que permitirá estruturar estratégias para adequação da situação e replicação do estudo em outras comunidades.
\end{abstract}

Palavras-chave: Ecologia urbana; fauna urbana; zoonoses.

\section{Domestic Animals and the Risk of Transmission of Pathogens for Wild Fauna in the Surrounding Area of Tijuca National Park}

ABSTRACT - Domestic animals are potential carriers of pathogenic agents, endangering wildlife, a common threat in urban environments, such as Tijuca National Park (PNT) and its buffer zone, where they live in great numbers in the surrounding communities. The Rio de Janeiro's Botanical Garden (JBRJ), such as the PNT, is pressured by urbanization, harboring at the PNT's borders, a community known as Horto $(\mathrm{CH})$, circumstances which brings wildlife, domestic animals and people closer. Pathogens can devastate wild populations, or, conversely, serve as an amplifier of infectious pathogens, circumventing controlactions of public health, thus, it is essential to know the health conditions, maintenance and management characteristics of domestic animals around the protected areas, in order to plan wildlife protection actions. This study's objective is to identify the potential presence of infectious risk agents to wildlife, by estimating domestic animals residing there and an inventory of possible infectious agents. For this we used questionnaires having as informants $\mathrm{CH}$ residents and veterinarians of the area, as well as data from the JBRJ's Fauna Conservation Team that served as a support for the analyzes. Community animals were not represented in local clinics records of visits, with unvaccinated and neglected animals, especially cats. We consider that there is 
a risk to native fauna at various levels and specially, the risk of reemergence of feline rabies. From the obtained results we can understand characteristics and beliefs of the community, being able to structure strategies for adequacy of the situation and replication of the study in other communities.

Keywords: Urban ecology; urban fauna; zoonoses.

\section{Animales domésticos y el riesgo de transmisión de Patógenos para la fauna salvaje en los alrededores del Parque Nacional Tijuca}

RESUMEN - Los animales domésticos son potencialmente portadores de patógenos de riesgo para la fauna nativa, lo que constituye una amenaza constante en las zonas urbanas, como el Parque Nacional de Tijuca (PNT) y su zona de amortiguamiento, donde viven en grandes cantidades en las comunidades circundantes. Al igual que el PNT, el Jardim Botânico do Rio de Janeiro (JBRJ) está bajo la presión de la urbanización, albergando, en la frontera con el PNT, una comunidad conocida como Horto $(\mathrm{CH})$, una situación que reúne a la fauna nativa, los animales domésticos y el hombre. Es esencial conocer las características de salud, mantenimiento y manejo de los animales domésticos en las cercanías de las áreas protegidas para planificar acciones de protección contra la fauna silvestre, ya que los agentes etiológicos pueden devastar las poblaciones silvestres o, a la inversa, servir como un amplificador de patógenos infecciosos, reduciendo la eficiencia de las acciones de control de salud pública. El objetivo de este trabajo fue identificar la posible presencia de agentes infecciosos en riesgo para la fauna silvestre, haciendo una estimación de los animales domésticos domiciliados allí y un inventario de posibles agentes patógenos. Utilizamos cuestionarios con informantes que viven en $\mathrm{CHe}$, veterinarios de la región y datos del Equipo de Conservación de Fauna del JBRJ, que sirvió de apoyo para los análisis. Los animales de la comunidad no están representados en los registros de visitas en las clínicas de la región, incluso hay animales no vacunados y descuidados, especialmente gatos. Consideramos que existe un riesgo para la fauna nativa en diferentes niveles y riesgo de resurgimiento de la rabia felina, principalmente. A partir de los resultados obtenidos, podemos entender las características y creencias de la comunidad, pudiendo estructurar estrategias para adaptar la situación y replicar el estudio en otras comunidades.

Palabras clave: Ecología urbana; fauna urbana; zoonosis.

\section{Introdução}

A conservação da fauna autóctone é inerente ao objetivo das unidades de conservação (UCs) e, entre os diversos fatores de pressão para a fauna nativa, estão a destruição $e$ fragmentação de seus habitat, a caça e o extermínio de presas (Jorge 2008), além de questões sanitárias. Essas questões estão em foco no cenário atual, com grande importância para a proteção da vida silvestre em situações de proximidade com o homem (Funk et al. 2001). A introdução de espécies invasoras é ameaça grave à biodiversidade mundial (Brasil 2011), entre outras razões, por introduzir agentes patogênicos infecciosos letais às populações silvestres (Morell 1994, Primack \& Rodrigues 2002, Lindenmayer \& Burgman 2005, Reed \& Merenlender 2011). Cães e gatos são portadores potenciais de diversos agentes etiológicos de risco para a fauna nativa (Marks \& Duncan 2009). Essa ameaça está sobretudo presente em áreas urbanas, como o Parque Nacional da Tijuca (PNT) e entorno, onde existe grande número desses animais vivendo em comunidades humanas. Espécies silvestres de hábitos mais generalistas tendem a se aproximar do homem de maneira voluntária, usando recursos como lixo e alimentos dos animais domésticos, $e$ agindo como carreadores de parasitos $e$ agentes etiológicos entre os ambientes. No caso de matas pressionadas antropicamente, ações humanas influenciam a movimentação de fauna, principalmente quando o projeto urbanístico é falho ou insipiente. Populações silvestres vivendo em áreas urbanas são passíveis de impactos constantes que resultam da expansão das cidades (Jones et al. 2013). O aumento da densidade de animais domésticos, como cães e gatos, nos países em desenvolvimento, associado à fragmentação de habitat, afeta negativamente as populações silvestres (Costa et al. 2005, Krauze-Gryz et al. 2012). A presença de presas compartilhadas entre animais domésticos e silvestres em áreas urbanas é, potencialmente, fator de risco aos animais, com transmissão mútua de patógenos (Marks \& Duncan 2009). 
Nesse contexto, é imprescindível conhecer as características de saúde, manutenção e manejo de cães e gatos no entorno do PNT e de outras UCs para o planejamento de ações de proteção à fauna silvestre, assim como informar aos proprietários sobre posse responsável, principal forma de controle de animais domésticos. É preciso avaliar as condições sanitárias, tanto de animais silvestres quanto de domésticos, a fim de conhecer e prevenir riscos sanitários decorrentes desse contato, já que possíveis epidemias podem devastar populações silvestres, ou, em via inversa, servirem estas como hospedeiras amplificadoras de agentes patogênicos infecciosos, afetando ações de controle das autoridades da saúde pública (Jorge 2008). A identificação da presença de patógenos potencialmente compartilhados entre animais domésticos e silvestres que vivem nas imediações ou no interior do PNT, e das condições e riscos de transmissão, é de fundamental importância para a implementação de programas de manejo de animais domésticos no entorno ou dentro da unidade. Compreender as condições de manejo e permanência da fauna doméstica, os riscos reais de contato, a predação, a troca de patógenos e outras relações com a fauna silvestre, além do imaginário de crenças dos proprietários e sua relação com essa fauna e o meio ambiente, poderá estabelecer os parâmetros para a criação de estratégias no monitoramento da fauna no local (Hughes \& MacDonalds 2013).

O objetivo principal deste estudo é identificar a presença de agentes infecciosos de risco para a fauna silvestre, possivelmente circulantes na área do Jardim Botânico do Rio de Janeiro (JBRJ) e no entorno, zona de amortecimento do PNT. Os objetivos específicos são: a) realizar estimativa de animais domésticos domiciliados no entorno do JBRJ, especificamente na Comunidade do Horto $(\mathrm{CH})$, investigando os hábitos dos moradores em relação à criação desses animais e ao convívio com a fauna silvestre; b) realizar inventário dos possíveis agentes infecciosos presentes nos animais domésticos da área, com foco em cães e gatos, e seus riscos para fauna silvestre.

\section{Material e Métodos}

A metodologia do presente estudo se configura como de caráter qualitativo, com o uso de diferentes estratégias de coleta de dados e distintas amostras. Foram usados como informantes os moradores da $\mathrm{CH}$ e veterinários da região. Dados da Equipe de Conservação da Fauna do Jardim Botânico do Rio de Janeiro (Fauna/JBRJ) serviram de apoio para a análise dos dados.

\section{Área de estudo}

O JBRJ possui área verde considerada Reserva da Biosfera pela UNESCO. Além do Arboreto cultivado, o JBRJ possui área de Mata Atlântica coberta por floresta secundária contígua ao PNT e ao Parque da Cidade, abrangendo $1.506 .303 \mathrm{~m}^{2}$, em encosta contígua ao Maciço da Tijuca, coberta por floresta secundária $e$ compondo a Serra da Carioca, por onde a fauna silvestre circula livremente. O JBRJ é, portanto, um importante corredor ecológico e área de amortecimento do PNT, além de área de ocorrência e permanência de fauna nativa, o que faz com que tenha importância intrínseca como área de preservação in situ de fauna. Exatamente entre o JBRJ e o PNT está situada a área conhecida como Comunidade do Horto, com cerca de 600 famílias vivendo em $1.350 .757 \mathrm{~m}^{2}$ (IPJB 2003), situação que favorece o contato entre a fauna nativa, animais domésticos e o homem.

\section{Coleta de dados}

Foram aplicados questionários compostos por questões fechadas $e$ abertas com o objetivo de avaliar aspectos referentes aos cuidados veterinários com os animais domésticos, hábitos de higiene, patógenos possivelmente circulantes no ambiente, relação dos interlocutores e dos animais domésticos locais com o meio ambiente, e posse responsável.

A partir de levantamento, através de consulta ao Google, das clínicas veterinárias da área adjacente à $\mathrm{CH}$, nos bairros da Gávea $e$ Jardim Botânico, foram selecionadas clínicas para as entrevistas. Os critérios de seleção das clínicas veterinárias levantadas para a aplicação do questionário foram: a) estabelecimentos que realizassem exames e consultas; b) proximidade com a $\mathrm{CH}$ suficiente para que o morador pudesse chegar à clínica a pé. Todas as clínicas levantadas foram contatadas e informadas dos objetivos do questionário e solicitadas a responder, através de seus veterinários responsáveis. 
Participaram do estudo sete veterinários de cinco clínicas, dentre as oito clínicas que se enquadravam nos critérios deste estudo. Em duas clínicas, os veterinários preferiram não responder. O questionário foi composto por questões fechadas e abertas, referentes ao período de 01/01/2016 a 31/12/2016. Para a construção do instrumento foi utilizada a escala de Likert em questões que tinham como objetivo mensurar o grau de concordância com a questão proposta. Foram construídas escalas clássicas, de cinco níveis, e escalas para aproximação, com dez níveis (Dalmoro \& Vieira 2013). Aplicou-se o questionário ao veterinário responsável pela clínica, que foi informado do objetivo da pesquisa e de que sua participação era voluntária, com a garantia de anonimato. Os dados aferidos foram tabulados em planilha Excel versão 2010, para a aplicação de estatística descritiva. Compararam-se as respostas obtidas com as respostas fornecidas pelos moradores a fim de identificar se os problemas que os moradores enfrentavam estavam refletidos nas informações prestadas pelos veterinários. Também se realizou a Análise do Conteúdo (Bardin 2011) para a construção de categorias que aglutinassem respostas por temas importantes.
Como critério de inclusão na amostra, apenas as residências contidas no perímetro descrito pelo Plano Diretor do JBRJ (Brasil 2013) foram consideradas. Esse perímetro inclui o entorno do JBRJ, onde está situada a $\mathrm{CH}$, que se divide, grosso modo, em: residências próximas à Escola Nacional de Botânica Tropical, ao Grotão, ao Morro das Margaridas; residências próximas à Rua Pacheco Leão e ao Morro da Titica (Figura 1). Foram consideradas apenas as residências que possuíam animais domésticos e cujos responsáveis, maiores de 18 anos, estivessem presentes no momento da visita $e$ aceitassem participar voluntariamente da pesquisa. Das cerca de 600 residências, 129 participaram do estudo, perfazendo, aproximadamente, $21,5 \%$ do total de casas no perímetro selecionado. A amostra foi definida a partir do critério de amostragem não probabilística por conveniência (Bussab \& Morettin 2002, Hill \& Hill 2005, Magalhaes \& Lima 2008). O questionário buscou investigar número de animais, características da criação, histórico veterinário, relação dos animais domésticos locais com o meio ambiente e histórico de caça/acesso de fauna silvestre no ambiente. Entre junho de 2016 e junho de 2017, realizou-se a coleta de dados. Todos os

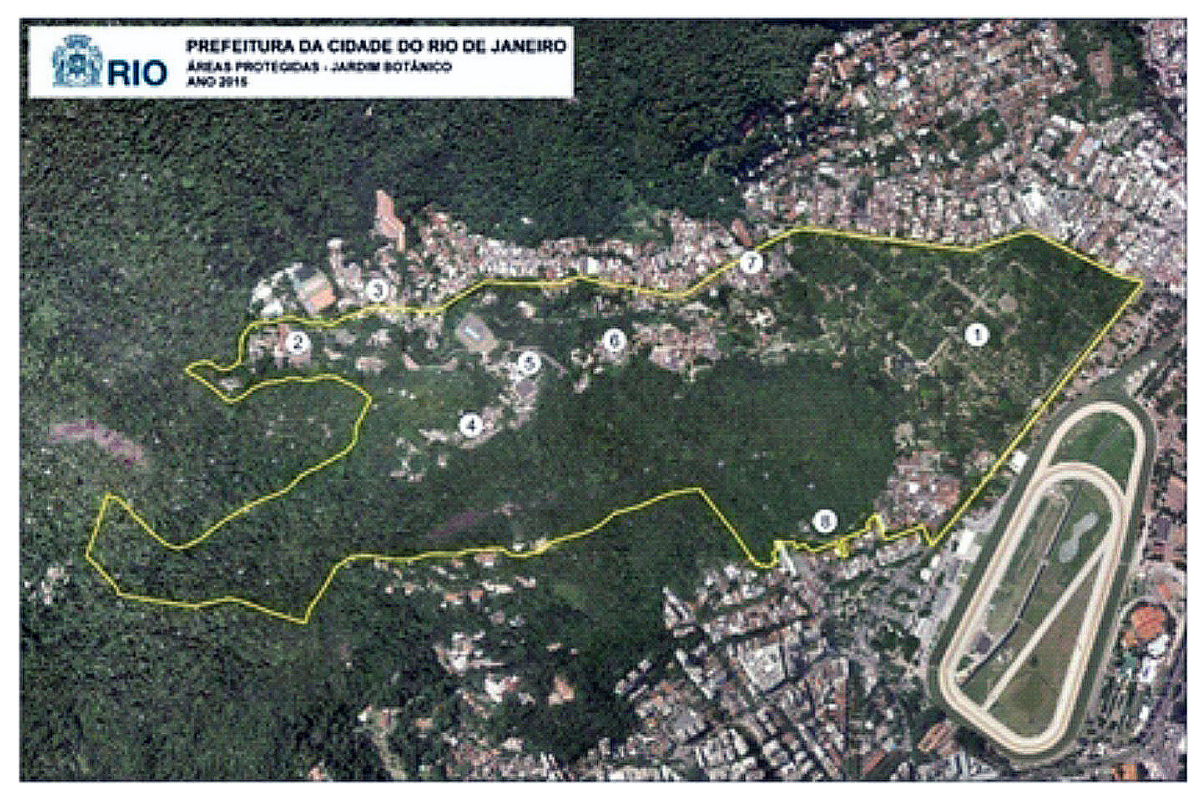

Figura 1 - Mapa do perímetro do Jardim Botânico do Rio de Janeiro. Os números correspondem a: 1) Arboreto do JBRJ; 2) Solar da Imperatriz - Escola Nacional de Botânica Tropical; 3) Comunidade do Horto residências próximas à Escola Nacional de Botânica Tropical; 4) Comunidade do Horto - Grotão; 5) Serpro; 6) Comunidade do Horto - Morro das Margaridas; 7) Comunidade do Horto - residências próximas à rua Pacheco Leão; e 8) Comunidade do Horto - Morro da Titica. Figura adaptada a partir de Rio de Janeiro (2015). 
questionários respondidos foram numerados para referenciá-los na planilha que serviu de matriz dos dados. Aos respondentes foi informado o objetivo da pesquisa e que sua participação era voluntária, com a garantia de anonimato. Os dados aferidos foram tabulados em planilha Excel versão 2010, para posterior aplicação de estatística descritiva. Também se realizou a Análise do Conteúdo (Bardin 2011) para construir categorias que permitissem aglutinar as respostas por temas importantes. Os dados da FAUNA-JBRJ, lotada na Coordenação de Conservação de Área Verde do JBRJ, foram obtidos a partir da consulta ao relatório de trabalho do grupo entre os anos de 2013 e 2017. A partir do socorro de fauna, a FAUNA-JBRJ mantém uma base de dados com o número de animais atendidos e os aspectos relevantes dos atendimentos, como características dos casos encontrados, localização, destinações, diagnósticos, entre outros, gerando relatórios periódicos sobre as atividades e ocorrências da fauna silvestre no JBRJ.

\section{Resultados}

A partir do relatório da FAUNA-JBRJ (Brasil 2018), observamos a constante presença de fauna doméstica no interior e nas imediações do JBRJ. No período entre 01/2013 e 12/2017, foram resgatados/manejados, no interior do JBRJ, 1.269 animais, contemplando pelo menos 133 espécies, sendo 30 de mamíferos ( $\mathrm{N}=532$ manejos), 69 de aves $(\mathrm{N}=325), 18$ de répteis $(\mathrm{N}=374)$, cinco de anfíbios $(\mathrm{N}=19)$ e seis de peixes $(\mathrm{N}=18)$. Os animais silvestres mais comuns foram Didelphis aurita $(16 \%, \mathrm{~N}=205)$, Callithrix sp. $(9 \%, \mathrm{~N}=110)$, Boa constrictor (5\%, N=69), Columba livia $(4 \%, \mathrm{~N}=51)$, Coendou spinosus $(3 \%, \mathrm{~N}=41)$, Ramphastos vitellinus ( $3 \%, \mathrm{~N}=38)$ e Bradypus variegatus $(2 \%, \mathrm{~N}=30)$. Entre os animais domésticos, considerando-se como domésticos animais de trabalho ou criação, como cães, gatos, pássaros de gaiola, cágados alóctones criados como pet, entre outros, os manejos/resgates representaram $23 \%$ ( $N=288$ animais) do total de resgates no período. Desse total, triaram-se 50 gatos domésticos e sete cães. De forma geral, gatos domésticos repre-sentam $4 \%$ dos manejos, sendo a sexta espécie mais resgatada, e cães domésticos são a $33^{\mathrm{a}}$ espécie mais manejada (1\%). Considerandose apenas os mamíferos, com pelo menos 30 espécies citadas em 532 manejos, gatos são a terceira espécie mais manejada $(9 \%$ da amostra de mamíferos) e cães são a décima espécie mais manejada (1\%). Ainda segundo a FAUNA-JBRJ, esse número de manejos não reflete a totalidade de animais domésticos presentes no JBRJ, sendo apontados os gatos vagantes e semidomiciliados como um problema de grandes proporções, com avistamentos diários e constantes, e cães fugitivos $e$ vagantes como problema pontual.

Entre animais domésticos, há manejo de cágado tigre-d'água (Trachemys sp.), resgates de passeriformes domesticados de diversas espécies, calopsitas (Nynphicus holandicus), jabutis domesticados (Chelonoidis carbonaria), patos domésticos (Cairina sp.), preás domésticos (Cavia porcellus) e roedores (silvestres ou não). Da mesma forma, o relatório apresenta dez manejos diretos de mamíferos da classe Carnivora (Cerdocyon thous, Procyon cancrivoros e Nasua nasua), dado importante pela proximidade taxonômica com cães e gatos domésticos, e 205 manejos diretos de $D$. aurita, que costumam entrar nas propriedades e são, muitas vezes, presas de animais domésticos.

\section{Questionários}

Foram identificadas oito clínicas veterinárias na região e realizadas sete entrevistas. Em uma das clínicas, dois veterinários responderam os questionários. Uma das clínicas realiza apenas exames laboratoriais. Duas clínicas não responderam. O valor médio das consultas nas clínicas é de $R \$ 271,45$, variando entre $R \$ 200$ e $\mathrm{R} \$ 350$. Estima-se que, por ano, sejam realizados 12.430 atendimentos em cães (Média $=1.775$ atendimento/ano/clínica) e 6.382 em gatos (Média $=911$ atendimentos/ano/clínica), podendo referir-se ao mesmo animal, em consultas, já que não foi feita diferenciação pelos entrevistados, podendo, desta forma, superestimar a quantidade de animais. Segundo os veterinários, cães são levados para acompanhamento clínico, em média, 1,5 vezes ao ano, e gatos, em média, 0,5 vezes ao ano. Todos os veterinários fizeram ressalva de que gatos são vacinados/vermifugados/consultados com menos frequência e/ou comprometimento de seus tutores do que cães.

Apenas duas clínicas atendem animais domésticos considerados exóticos, como calopsitas, hamsters, papagaios, jabutis entre outros. Uma clínica indicou que esse tipo de atendimento é frequente, enquanto a outra indicou que é pouco frequente. 
Realizaram-se 129 entrevistas aos moradores da $\mathrm{CH}$. Deste total, foram inventariados 161 cães, distribuídos em 88 residências; 59 gatos, distribuídos em 31 residências; e 39 outros animais, entre pássaros de gaiola (23 animais em 11 residências), aves de criação - como patos e galinhas (11 animais em três casas) -, quelônios (quatro animais em três casas) e porquinhos-daíndia (um animal em uma casa). Segundo os dados levantados, são, em média, 1,26 cães e 1,9 gatos por residência. Dadas as condições das comunidades pobres do Rio de Janeiro, também a $\mathrm{CH}$ possui condições que impossibilitam a determinação do número exato de residências. Deste modo, utilizaram-se os dados do Plano Diretor do Jardim Botânico do Rio de Janeiro (IPJB 2003) que estima o número de 600 residências. Portanto, a amostra de residências pesquisadas se aproxima do quartil das existentes no local. Cabe ressaltar que, durante o período de coleta de dados, houve eventos de reintegração de posse que criaram tensionamento na região, impossibilitando a continuidade do processo de coleta de dados. É importante destacar que o número de animais avistados é maior que o de animais inventariados. Além disso, não foi possível realizar as entrevistas em todas as casas, mesmo com avistamentos ou outras confirmações, como latidos ou outras vocalizações de animais domésticos no local, o que pode subestimar o número de animais.

\section{Comparação da percepção de hábitos de cuidados veterinários}

Buscamos aferir e classificar os níveis de cuidados veterinários básicos dispensados a animais domésticos, segundo as clínicas veterinárias e os proprietários na $\mathrm{CH}$, investigando consultas preventivas, vacinação e vermifugação de cães, gatos e outros animais. Os resultados aferidos quanto aos cuidados veterinários foram organizados na Tabela 1.

Os moradores da $\mathrm{CH}$ informaram que nunca levaram ao veterinário $2 \%$ dos gatos $(\mathrm{N}=1)$, nunca tendo sido vacinados $3 \%$ dos cães $(\mathrm{N}=4)$ e $10 \%$ dos gatos $(\mathrm{N}=6)$ e, majoritariamente, cães são levados ao veterinário somente quando há emergência a ser atendida (35\% dos cães).

Animais domésticos não convencionais representaram importante variável, com muitos avistamentos de patos e frangos sem que fosse possível identificar os donos. Os dados compilados apresentam um universo pequeno, porém bastante representativo dos animais em questão. Neste caso, a amostra é muito variada e descontínua, e a maioria dos respondentes desconhecia os dados de cuidados veterinários dos seus animais, o que torna o resultado pouco conclusivo. Apenas três animais foram levados ao veterinário uma vez ao ano, $e$ apenas um animal foi vermifugado.

Tabela 1 - Comparativo de hábitos de cuidados veterinários, baseado em entrevistas às clínicas pesquisadas e aos proprietários da $\mathrm{CH}$.

\begin{tabular}{|c|c|c|c|c|c|}
\hline & \multirow[b]{2}{*}{ Frequência } & \multicolumn{2}{|c|}{ Cães } & \multicolumn{2}{|c|}{ Gatos } \\
\hline & & Clínicas & Proprietários & Clínicas & Proprietários \\
\hline \multirow{6}{*}{$\begin{array}{l}\text { Acompanhamento } \\
\text { preventivo ao veterinário }\end{array}$} & $1 \mathrm{x}$ ano & $60 \%$ & $17 \%$ & $45 \%$ & $42 \%$ \\
\hline & $2 \mathrm{x}$ ano & $39 \%$ & $19 \%$ & - & $3 \%$ \\
\hline & $3 \mathrm{x}$ ano & - & $27 \%$ & - & $14 \%$ \\
\hline & Emergência & $1 \%$ & $35 \%$ & $55 \%$ & $39 \%$ \\
\hline & Não informado & - & $1 \%$ & - & $0 \%$ \\
\hline & Nunca & - & $1 \%$ & - & $2 \%$ \\
\hline \multirow{4}{*}{ Vacinação } & Protocolo veterinário & $75 \%$ & $84 \%$ & $87 \%$ & $59 \%$ \\
\hline & Campanha & $25 \%$ & $12 \%$ & - & $31 \%$ \\
\hline & Não informado & - & $1 \%$ & - & $0 \%$ \\
\hline & Não vacina & - & $3 \%$ & $13 \%$ & $10 \%$ \\
\hline \multirow{6}{*}{ Vermifugação } & Protocolo veterinário & $51 \%$ & $3 \%$ & $24 \%$ & - \\
\hline & $1 \mathrm{x}$ ano & $8 \%$ & $35 \%$ & $31 \%$ & $47 \%$ \\
\hline & $2 \mathrm{x}$ ano & $35 \%$ & $35 \%$ & - & $27 \%$ \\
\hline & $3 \mathrm{x}$ ano & $6 \%$ & $12 \%$ & - & $5 \%$ \\
\hline & Não informado & - & $20 \%$ & - & $2 \%$ \\
\hline & Não vermifuga & - & $3 \%$ & $45 \%$ & $19 \%$ \\
\hline
\end{tabular}

Desconsiderando-se a Clínica 5 , que somente realiza exames laboratoriais 


\section{Hábitos de higiene e cuidados com animais domésticos}

Procuramos levantar os hábitos dos proprietários em relação aos cuidados gerais no trato com os animais: higiene, descarte de resíduos, hábitos alimentares e disponibilização de alimento. Foram buscados fatores que pudessem ser prejudiciais à fauna, atraindo-a para junto das moradias, facilitando a transmissão de agentes patogênicos ou outros aspectos de interação possíveis. Verificaram-se crenças e hábitos a serem abordados para o esclarecimento da população.

$\mathrm{O}$ descarte indevido de fezes no rio, mato ou rua, é recorrente. Realizou-se um cruzamento dessas informações com os hábitos de cuidados veterinários gerais, segundo a informação dos proprietários, de forma a compreendermos qual tipo de contaminação poderia estar acontecendo por essas vias, conforme apresentado na Tabela 2.

Tabela 2 - Hábitos de descarte de fezes de animais domésticos associado ao protocolo veterinário utilizado, segundo informações dos proprietários de animais domésticos na $\mathrm{CH}$.

\begin{tabular}{|c|c|c|c|c|c|c|c|c|}
\hline \multirow[t]{2}{*}{ ANIMAIS } & & & \multicolumn{6}{|c|}{ DESCARTE DE FEZES SEGUNDO OS PROPRIETÁRIOS } \\
\hline & \multicolumn{2}{|c|}{$\begin{array}{c}\text { CUIDADOS VETERINÁRIOS REALIZADOS } \\
\text { POR PROPRIETÁRIOS }\end{array}$} & Lixo & Esgoto & Mato/ rio & $\begin{array}{l}\text { Rua / } \\
\text { varrição }\end{array}$ & Outro & $\begin{array}{l}\text { Não } \\
\text { respondeu }\end{array}$ \\
\hline \multirow{12}{*}{ CÃES } & \multirow{4}{*}{ Freq. vet. } & Pelo menos $1 \mathrm{x}$ ano & 71 & 12 & 1 & 17 & - & - \\
\hline & & Emergência & 33 & 2 & 3 & 17 & 1 & - \\
\hline & & Nunca & 1 & - & 1 & - & - & - \\
\hline & & Não respondeu & 2 & - & - & - & - & - \\
\hline & \multirow{4}{*}{ Vacina } & Protocolo veterinário & 94 & 14 & 4 & 23 & 1 & - \\
\hline & & Campanha & 10 & - & 1 & 9 & - & - \\
\hline & & Não vacina & 2 & - & - & 2 & - & - \\
\hline & & Não respondeu & 1 & - & - & - & - & - \\
\hline & \multirow{4}{*}{ Vermífugo } & Protocolo veterinário & 4 & - & - & - & - & - \\
\hline & & Pelo menos $1 \mathrm{x}$ ano & 85 & 13 & 5 & 28 & 1 & - \\
\hline & & Não vermifuga & 1 & - & 5 & 4 & - & - \\
\hline & & Não respondeu & 17 & 1 & - & - & - & 2 \\
\hline \multicolumn{3}{|c|}{ Total de descartes para cães: } & $66 \%$ & $9 \%$ & $2 \%$ & $22 \%$ & $1 \%$ & - \\
\hline \multirow{9}{*}{ GATOS } & \multirow{3}{*}{ Freq. vet. } & Pelo menos $1 \mathrm{x}$ ano & 32 & 1 & - & 2 & - & - \\
\hline & & Emergência & 9 & - & 1 & 12 & - & 1 \\
\hline & & Nunca & 1 & - & - & - & - & - \\
\hline & \multirow{3}{*}{ Vacina } & Protocolo veterinário & 32 & 1 & 1 & 1 & - & - \\
\hline & & Campanha & 8 & - & - & 10 & - & - \\
\hline & & Não vacina & 2 & - & - & 3 & - & 1 \\
\hline & \multirow{3}{*}{ Vermífugo } & Pelo menos $1 \mathrm{x}$ ano & 35 & 2 & 1 & 10 & - & - \\
\hline & & Não vermifuga & 7 & - & - & 3 & - & 1 \\
\hline & & Não respondeu & - & - & - & 1 & - & - \\
\hline \multicolumn{3}{|c|}{ Total de descartes para gatos: } & $\mathbf{7 1 \%}$ & $2 \%$ & $2 \%$ & $23 \%$ & - & $2 \%$ \\
\hline
\end{tabular}




\begin{tabular}{|c|c|c|c|c|c|c|c|c|}
\hline \multirow[t]{2}{*}{ ANIMAIS } & & & \multicolumn{6}{|c|}{ DESCARTE DE FEZES SEGUNDO OS PROPRIETÁRIOS } \\
\hline & \multicolumn{2}{|c|}{$\begin{array}{c}\text { CUIDADOS VETERINÁRIOS REALIZADOS } \\
\text { POR PROPRIETÁRIOS }\end{array}$} & Lixo & Esgoto & Mato/ rio & $\begin{array}{l}\text { Rua / } \\
\text { varrição }\end{array}$ & Outro & $\begin{array}{l}\text { Não } \\
\text { respondeu }\end{array}$ \\
\hline \multirow{11}{*}{$\begin{array}{l}\text { OUTROS } \\
\text { ANIMAIS }\end{array}$} & \multirow{4}{*}{ Freq. vet. } & Pelo menos $1 \mathrm{x}$ ano & 7 & - & - & 3 & - & 1 \\
\hline & & Emergência & 1 & - & - & - & - & - \\
\hline & & Nunca & & 2 & - & 2 & - & - \\
\hline & & Não respondeu & 8 & - & - & 1 & - & 14 \\
\hline & \multirow{3}{*}{ Vacina } & $\begin{array}{l}\text { Protocolo veterinário } \\
\text { para a espécie }\end{array}$ & 1 & - & - & 3 & - & 1 \\
\hline & & Não respondeu & 8 & & - & 1 & - & 14 \\
\hline & & Não vacina & 7 & 2 & - & 2 & - & - \\
\hline & \multirow{4}{*}{ Vermífugo } & Pelo menos $1 \mathrm{x}$ ano & & & - & 3 & - & - \\
\hline & & $\begin{array}{l}\text { Protocolo veterinário } \\
\text { para a espécie }\end{array}$ & 1 & - & - & - & - & - \\
\hline & & Nunca & 7 & 2 & - & 2 & - & - \\
\hline & & Não respondeu & 8 & & - & 1 & - & 15 \\
\hline \multicolumn{3}{|c|}{ Total de descartes para outros: } & $41 \%$ & $\mathbf{5 \%}$ & - & $15 \%$ & - & $39 \%$ \\
\hline
\end{tabular}

\section{Agentes patogênicos possivelmente circulantes no ambiente}

Nesta parte do questionário, buscou-se a percepção dos veterinários da área, segundo o seu entendimento, dos agentes patogênicos que consideravam importantes em sua prática regular. Os diagnósticos são clínicos, segundo a percepção e o entendimento dos veterinários na sua prática regular, e não necessariamente baseados em exames, podendo representar suspeitas não confirmadas (Tabela 3).

Tabela 3 - Agentes patogênicos possivelmente circulantes no meio ambiente no entorno do JBRJ e $\mathrm{CH}$, segundo a percepção clínica dos veterinários para o ano de 2016*.

\begin{tabular}{|c|c|c|c|c|c|c|c|c|c|}
\hline \multirow{2}{*}{$\begin{array}{c}\text { Agentes } \\
\text { patogênicos }\end{array}$} & \multirow[t]{2}{*}{$\begin{array}{l}\text { Babesiose } \\
\text { Erliquiose }\end{array}$} & \multirow[t]{2}{*}{ Cinomose } & \multirow[t]{2}{*}{$\begin{array}{l}\text { Parvovi- } \\
\text { rose }\end{array}$} & \multirow[t]{2}{*}{ Raiva } & \multirow[t]{2}{*}{$\begin{array}{l}\text { Leishi- } \\
\text { maniose }\end{array}$} & \multirow[t]{2}{*}{$\begin{array}{l}\text { Leptos- } \\
\text { pirose }\end{array}$} & \multirow[t]{2}{*}{$\begin{array}{l}\text { Toxoplas- } \\
\text { mose }\end{array}$} & \multicolumn{2}{|c|}{$\begin{array}{l}\text { Estimativa } \\
\text { atendimentos/ano por } \\
\text { espécie, por clínica }\end{array}$} \\
\hline & & & & & & & & Cães & Gatos \\
\hline CL 1 & 10 & 4 & 3 & 0 & 1 & 2 & 0 & 3120 & 1560 \\
\hline CL 2 & 6 & 3 & 0 & 0 & 1 & 0 & 1 & 700 & 200 \\
\hline CL 2 B & 1 & 7 & 0 & 0 & 1 & 1 & 1 & 970 & 820 \\
\hline CL 3 & 10 & 5 & 1 & 0 & 3 & 3 & 1 & 3120 & 2490 \\
\hline CL 4 & 3 & 5 & 1 & 0 & 4 & 0 & 0 & 1250 & 312 \\
\hline CL5 (exames) & 8 & 0 & 3 & 0 & 1 & 4 & 0 & 150 & 40 \\
\hline CL6 & 7 & 1 & 2 & 0 & 1 & 1 & 0 & 3120 & 960 \\
\hline $\begin{array}{l}\text { MÉDIA (segundo } \\
\text { a escala) }\end{array}$ & 6,428 & 3,571 & 1,428 & 0 & 1,714 & 1,571 & 0,428 & 12430 & 6382 \\
\hline $\begin{array}{l}\text { DESVIO } \\
\text { PADRÃO }\end{array}$ & 3,156 & 2,259 & 1,178 & 0 & 1,161 & 1,400 & 0,495 & $1.203,980$ & 806,056 \\
\hline
\end{tabular}

* Oferecendo-se Escala de Likert com valores de 0 a 10, em que: $0=$ inexistente e $10=$ muito frequente, foram feitas perguntas em relação à incidência de casos atendidos dos agentes patogênicos enumerados na primeira linha da tabela. Todas as respostas deveriam levar em consideração os atendimentos de cães e gatos, segundo a característica da patogenia. Todas as clínicas foram consideradas. 


\section{Relação dos animais domésticos locais com o meio ambiente e posse responsável}

Três clínicas relataram atender animais silvestres, considerando tratar-se de animais nativos da região, não domésticos. Usando-se a escala oferecida de $0=$ nunca a $5=$ muito frequente, uma clínica respondeu: $2=$ raro, e duas clínicas responderam $3=$ pouco frequente. Os animais mais citados foram os saguis (Callithrix sp.) $e$ gambás ( $D$. aurita). Citaram-se passeriformes sem especificação, gaviões, ouriços e macacos-prego. Todos os atendimentos foram realizados em animais que se acidentaram de alguma forma. Quanto a atendimentos com histórico de ataques de animais silvestres a domésticos, segundo a mesma escala, para cães, esse atendimento foi considerado: $2=$ raro, em três clínicas; $3=$ pouco frequente, em duas clínicas; e $5=$ muito frequente, em uma clínica. Os animais mais citados foram ouriços e serpentes. Uma das respondentes citou ataques por morcego em, pelo menos, três atendimentos diferentes, a animais na região, ainda que fora da comunidade em questão. Para gatos, apenas duas clínicas responderam que sim, sendo para as duas: $2=$ raro, e citando ataque por ratos e serpentes.

Buscamos investigar, na percepção dos proprietários, a relação dos animais domésticos com o meio ambiente, os hábitos de acesso ao exterior das casas e os hábitos observados de caça e predação, considerando como casa a construção da residência, o quintal cercado ou murado.

\section{Relação dos interlocutores com o meio ambiente}

Para conhecer a relação dos moradores da $\mathrm{CH}$ com a mata e a vida silvestre, foi perguntado se eles consideravam "positivo", "negativo" ou "indiferente". Considerou-se positiva a proximidade das residências com a mata $(88 \%$ dos entrevistados), negativa (6\%) e indiferente (6\%). A proximidade com animais silvestres foi vista como positiva ( $74 \%$ dos entrevistados), negativa ( $24 \%$ ) e indiferente $(6 \%)$.

Foram citados 27 "tipos" de animais (saguis, saimiris, macacos-prego, gambás, mãos-peladas, quatis, esquilos, tatus, ouriços, capivaras, ratos, cutias, tamanduás, pacas, morcegos, lagartos e outros répteis, jiboias e outras serpentes, aves diversas e, especificamente, tucanos, jacupembas, gaviões, garças, beija-flores e saracuras) avistados por $94 \%(\mathrm{~N}=121)$ dos moradores da $\mathrm{CH}$. Dos entrevistados, $54 \%$ afirmaram que os animais entram nas residências, quintais e propriedades; $29 \%(\mathrm{~N}=37)$ admitiram o costume de alimentar animais silvestres. Quanto aos animais domésticos vagantes, $74 \%(\mathrm{~N}=95)$ dos moradores afirmaram não alimentar.

\section{Discussão}

Cães e gatos podem transmitir mais de 30 zoonoses, além de outros agentes patogênicos (Lages 2009, Hughes \& Macdonald 2013), sendo possíveis portadores de agentes patogênicos contagiosos para animais silvestres e para o homem. É imprescindível, portanto, conhecer as características de saúde e manutenção desses animais no entorno das UCs, para planejamento de ações protetivas e preventivas (Costa et al. 2005, Chiarello et al. 2008, Jorge 2008).

Nossos resultados mostram que, enquanto $35 \%$ dos proprietários de cães da $\mathrm{CH}(\mathrm{N}=56)$ levam seus animais ao veterinário apenas em caso de emergência, nas clínicas os clientes têm o hábito de levá-los para acompanhamento, em média, 1,5 vezes ao ano, indicando que seu público não se encontra fortemente representado entre os moradores da $\mathrm{CH}$, apesar da proximidade. Gatos são minoria nos atendimentos clínicos, qualquer que seja o aspecto levantado, assim como são minoria em nosso levantamento, mas são presença constante no ambiente. A constatação de que os donos de animais domésticos da $\mathrm{CH}$ não levam seus animais ao veterinário pode ser atribuída ao nível socioeconômico da comunidade, como aponta Miranda Filho (2012), quando afirma que $71,7 \%$ das famílias ali residentes possuem renda de zero a cinco salários mínimos. Segundo dados da FAUNA/JBRJ, são resgatados, anualmente, em média, 10 gatos, ou 7,14 gatos para cada cão, não refletindo a pequena quantidade de animais domiciliados encontrados no levantamento. Considerando o fato de não serem resgatados todos os gatos avistados, mas somente os feridos, mortos ou filhotes órfãos, enquanto são resgatados tantos cães quanto o possível, percebe-se uma subavaliação da presença desses na área de estudo (Brasil 2018). Observamos o problema ético e sanitário das populações de gatos vagantes como desafio crescente para conservação ambiental, visto que, apesar de a taxa de mortalidade infantil 
em animais não domiciliados ser alta (até 75\%) $e$, somando os maciços esforços de esterilização, as populações continuam crescentes (Kilgour et al. 2017). Dos entrevistados da $\mathrm{CH}, 25 \%$ costuma alimentar cães e gatos vagantes, o que, associado à não esterilização de matrizes e padreadores, auxilia as altas taxas de reprodução. Além disso, a proximidade com o gatil do Jockey Club Brasileiro, com cerca de 1.400 gatos abrigados em semidomiciliamento (observação pessoal de GH 2019), aumenta o abandono de animais. A condição financeira dos moradores pode ser um fator de restrição ao uso das clínicas, pois o valor da consulta representaria alto impacto no orçamento dessas famílias.

Dez por cento dos proprietários de gatos na $\mathrm{CH}$ nunca vacinou seus animais. $\mathrm{O}$ contato destes com gatos vagantes possibilita troca de patógenos entre eles e outros animais, e com o homem. A raiva, p.ex., atinge praticamente todos os mamíferos, e gatos não vacinados podem ser contaminados por suas presas. Em países desenvolvidos, a ordem Carnivora é considerada a principal responsável por casos de raiva e, em países em desenvolvimento, os principais hospedeiros amplificadores são cães e gatos domésticos, quirópteros e carnívoros silvestres (Vasconcellos 2001).

Os resultados para questões de vermifugação apontam falhas na cobertura: dos entrevistados, $20 \%$ dos proprietários de cães não foram capazes de informar hábitos de vermifugação. Duas clínicas indicaram que proprietários de gatos não costumam vermifugar seus animais - no total, $45 \%$ dos gatos atendidos nas clínicas não são vermifugados, o que reflete a grande quantidade de animais não vermifugados pelos proprietários, entre os moradores da $\mathrm{CH}$ ( $19 \%$ da amostra). Apesar de os dados indicarem que os gatos atendidos nas clínicas, em geral, não são aqueles residentes na $\mathrm{CH}$, podem apontar uma tendência entre os criadores na região como um todo. Diversas parasitoses podem ser compartilhadas por humanos, cães, gatos e fauna local. A falta de vermifugação, ainda que não esteja refletindo em casos de toxoplasmose, p.ex., contribuiria para a distribuição de parasitoses no local.

Hábitos de higiene no descarte de fezes de animais domésticos possivelmente contaminados e hábitos inadequados na alimentação destes, como a disponibilização displicente de recursos alimentares, favorecem a manutenção de populações de gatos domésticos vagantes ou semidomiciliados (Ferreira et al. 2018) e podem causar a transmissão de agentes patogênicos. $\mathrm{O}$ descarte das fezes no lixo comum é a principal forma utilizada pelos proprietários na amostra. Quatis, mãos-peladas, primatas, ratos e gambás, além de animais domésticos, são atraídos pelo lixo $e$, ao revirarem as lixeiras, podem entrar em contato com as fezes. Esse descarte deve ser realizado separadamente do lixo orgânico, em lixeiras apropriadas, assim como deve ser evitado o descarte direto no rio, com contaminação direta do ambiente. As práticas de descarte comuns na $\mathrm{CH}$ são impróprias, portanto, e contrariam as recomendações internacionais sobre conservação de áreas de proteção ambiental urbana (Trzyna 2014). É preciso incentivar hábitos como alimentação da criação em horário específico e outras práticas que evitem o assédio de outros comensais. Hábitos tradicionais de alimentação de patos e galinhas com restos espalhados no terreiro e grande quantidade de sobras contribuem para a insalubridade na criação $e$ atração de fauna. A educação ambiental é indicada para a remediação dessa situação.

\section{Agentes patogênicos possivelmente circulantes no ambiente}

Segundo a percepção dos veterinários entrevistados, os agentes patogênicos mais comuns circulando na região são a babesiose $e$ a erliquiose, transmitidos por carrapatos. Os dois agentes patogênicos são de grande importância zoonótica e estão relacionados à ocorrência do hospedeiro (Silva 2015, Dias \& Ferreira 2016). Ainda que Oliveira (2017), em levantamento preliminar de ectoparasitas em mamíferos silvestres resgatados pela FAUNA/JBRJ, não tenha encontrado carrapatos Rhipicephalus sanguineus, sabe-se que os dois agentes patogênicos estão presentes na localidade. Oliveira (2017) encontrou, no entanto, Amblyomma longirostre, A. ovale, A. varium elxodesloricatus em gambás, preguiças, ouriços-cacheiros, quatis, mãos-pelada e cachorros-do-mato. $\mathrm{O}$ mesmo estudo indica que os carrapatos acima são comumente associados à Rickettsia sp. e podem infestar animais domésticos $e$ humanos. O estudo encontrou, ainda, pulgas das espécies Ctenocephalides felis, associadas à Rickettsia sp. e Yersinia pestis, infestando gambás e mãos-pelada, sendo essas pulgas associadas, principalmente, ao gato-doméstico (Horta et al. 2005, 2007), havendo casos conhecidos de 
infestação em cães também. A pulga da espécie Barbonolla sp. foi encontrada em cachorrosdo-mato e é associada, principalmente, a ratos e cães (Leulmi et al. 2014), podendo transmitir Rickettsia typhi e Barbonolla sp. A presença de ectoparasitas característicos de animais domésticos na fauna silvestre local, inclusive com infestação associada de mais de uma espécie, pode indicar a proximidade dos animais silvestres com os animais domésticos, resultando em intercâmbio parasitário (Oliveira 2017).

A cinomose aparece em terceiro lugar, com média de 3,5 pontos em 10 pontos, na escala de Likert, com valores de 0 a 10 , em que: $0=$ inexistente; e $10=$ muito frequente, segundo os informantes veterinários. Ainda que não seja patogenia comum, sua presença é fator de risco, pois pode ser considerado como um dos agentes patogênicos infecciosos mais impactantes à conservação de carnívoros de vida livre, com alto grau de mortalidade em populações silvestres (Davidson et al. 1992, Primack \& Rodrigues 2002, Lindenmayer \& Burgman 2005, Jorge 2008). Sua forma de transmissão via contato direto com animais infectados, ou indireto, com objetos contaminados através de secreções e excreções (Catroxo 2003), exige cuidados na disponibilização e no descarte de alimentação de animais domésticos, evitando contaminação cruzada.

A parvovirose encontra pouca pontuação, com média de 1,428 ponto em 10 pontos, na escala de Likert, com valores de 0 a 10 , em que: $0=$ inexistente; e $10=$ muito frequente. A permanência do parvovírus no ambiente, em condições ideais, pode ser de até um ano (Gordon \& Angrick 1986), tornando-a potencialmente perigosa para diversas espécies de felídeos, canídeos, mustelídeos e procionídeos (Cleaveland et al. 2006), via dejetos contaminados de animais domésticos.

No Brasil, o cão é o principal hospedeiro amplificador, no ciclo urbano, da raiva, principalmente no Norte e Nordeste, e os morcegos, no ciclo silvestre, por todo o país (Jorge 2008, Peixoto 2012). Apesar dos esforços para controle da patogenia nas Américas, com ações como o Programa Nacional de Profilaxia da Raiva Humana e o Plano de Ação para Eliminação da Raiva Urbana nas Principais Cidades da América Latina, elaborado em 1983 pela Organização Pan-Americana da Saúde (Wada et al. 2011), verifica-se a necessidade de vigilância epidemiológica em espécies silvestres, especialmente morcegos, e maior abrangência da ação, incluindo cidades menores.

Não foram encontrados casos de raiva no presente estudo; porém, relatos de um veterinário respondente dão conta de pelo menos três cães nos bairros do Jardim Botânico e Gávea que teriam sofrido ataque de morcegos, podendo haver risco para a transmissão de raiva. São conhecidas duas espécies de morcegos hematófagos para a região do JBRJ e PNT: Desmodus rotundus e Diphylla ecaudata (Esbérard 2003). Animais domésticos não domiciliados, como gatos vagantes, podem predar morcegos, mesmo não hematófagos, contraindo e transmitindo a patogenia para outros animais e para o homem. Sendo a raiva uma zoonose de grande importância mundial, fatal em quase $100 \%$ dos casos, e o controle e prevenção de custo elevado (Lages 2009), a presença de animais não vacinados é preocupante, sendo possível o ressurgimento como problema de saúde pública (Jorge 2008).

O último caso de raiva humana na cidade do Rio de Janeiro foi registrado em 1984, e o último caso canino em 1995. No entanto, o vírus está presente em ambiente silvestre, principalmente entre morcegos, conforme mostrado por dados do Centro de Controle de Zoonoses da prefeitura do Rio de Janeiro (Rio de Janeiro 2016a, 2017, 2018 a, b).

Animais domésticos vagantes em grande número dificultam a manutenção da cobertura vacinal acima de $75 \%$ (Lages 2009). Ainda que, segundo Lages (2009), nas Américas, 65\% dos casos de raiva humana tenham sido causados diretamente por cães, $14,7 \%$ por morcegos e apenas 3,3\% dos casos por gatos, o hábito de caça $e$ a cobertura vacinal desses animais abaixo da recomendada na maioria dos municípios brasileiros, torna esses animais frequentemente responsáveis por realizar essa ponte, incluindose casos humanos fatais. A pressão ambiental e a ocupação humana facilitam essa cadeia ao aproximar gatos, cães e homem de morcegos $e$ outros animais suscetíveis, facilitando acidentes e transmissão de raiva e outras zoonoses (Jorge 2008, Lages 2009, Peixoto 2012).

A leishmaniose encontrou média igual a 1,714 pontoem 10 pontos, na escala de Likert, com valores de 0 a 10 , em que: $0=$ inexistente; $e$ $10=$ muito frequente. É patogenia de comunicação 
compulsória (Rio de Janeiro 2013). Agentes da prefeitura visitam residências para testagem de cães, controlando essa patogenia de forma incisiva. Relatórios da Prefeitura do JBRJ e imediações não indicam a presença do flebotomíneo (mosquitopalha), seu vetor, na localidade. Um levantamento realizado na área também não indica a presença do vetor (Mocellin et al. 2009). Os dois levantamentos chegam apenas à borda da mata, não sendo possível excluir completamente a presença do flebótomo no seu interior. Segundo a Prefeitura do Rio de Janeiro, em série histórica sobre casos confirmados de leishmaniose visceral humana, de 01/2007 a 07/2018 foram registrados 24 casos, sem ocorrências na área da $\mathrm{CH}$ (Rio de Janeiro 2018g). Em área urbana, o principal hospedeiro amplificador é o cão e, em áreas silvestres ou rurais, canídeos e Didelphis sp. (Brasil 2014).

A média para leptospirose é de 1,571ponto em 10 pontos, na escala de Likert, com valores de 0 a 10 , em que: $0=$ inexistente; e $10=$ muito frequente. Essa patogenia recebeu pontuações discrepantes, variando de 0 a 4, com informantes relatando nunca terem visto casos, em anos de trabalho, e outros que consideram relativamente comum. Como zoonose de importância mundial, com cães entre os principais hospedeiros amplificadores urbanos, e contaminação pelo contato com urina ou água contaminada (Brasil 2014), é preocupante a declaração de proprietários quanto ao descarte displicente de dejetos animais. Ainda que seja incomum em cães domiciliados e não tenha sido apontada como comum pelos veterinários entrevistados, pode, potencialmente, contaminar animais silvestres que vasculhem o lixo ou se aproximem de residências, o que é ainda mais preocupante quando pouco se sabe sobre a sua importância no ciclo e transmissão (Fornazari \& Langoni 2014). Sobre a presença de Leptospira em animais selvagens, Stefan et al. (2013) apontam que animais de diversas ordens de mamíferos podem agir como reservatório, transmitindo para animais domésticos, além de serem afetados pela disseminação do agente patológico.

\section{Considerações Finais}

Em sua maioria, com exceção da babesiose/ erliquiose e leishmaniose, os agentes patogênicos relacionados demandam controle higiênico profilático. O descarte indevido de dejetos dos animais domésticos é potencialmente perigoso para a fauna, sobretudo quando realizado juntamente com o lixo orgânico, que atrai os animais oportunistas. Por meio da educação ambiental, é preciso criar protocolo para essa situação, separando o lixo orgânico das fezes $e$ material de varrição contaminado, e descartando o lixo em caçambas apropriadas. Hábitos como lavagem de calçadas e terreiros com o despejo da água diretamente no meio precisam ser substituídos por técnicas menos ofensivas, além da eliminação de potenciais contaminações, com a utilização de lixeiras adequadas e combate ao descarte indevido, o que diminuirá a presença de parasitos intestinais circulantes (Trzyna 2014). O controle de carrapatos e pulgas nos animais domésticos é de suma importância para o controle da babesiose/erliquiose e outros agentes patogênicos. Segundo Oliveira (2017), todos os ectoparasitas encontrados no local são vetores de agentes patogênicos possivelmente transmissíveis ao homem. A vacinação contra erliquiose é uma possibilidade, porém, ainda cara.

Animais domésticos não convencionais encontram pouco atendimento veterinário na área, e seus proprietários não têm como hábito levá-los ao veterinário, conforme discutimos acima. Essa lacuna pode ser responsável pela circulação de agentes patogênicos inesperados, já que existe grande diversidade nas espécies, e algumas são conhecidas por abrigar zoonoses, como frangos e patos. Neste aspecto, um estudo aprofundado é necessário. Jorge (2008) aponta a necessidade de monitoramento da exposição a agentes patogênicos transmitidos por animais domésticos às populações de animais silvestres como parte do plano de manejo das UCs e áreas de amortecimento. Além disso, um controle de predação, invasão e hibridação se faz necessário para que a diretriz de proteção à fauna possa ser atendida, segundo o mesmo autor, que ressalta, ainda, a necessidade de vacinação e vermifugação dos animais domésticos como forma de proteção tanto à fauna nativa quanto ao homem.

Acreditamos que o risco de transmissão de agentes patogênicos na localidade é real, sendo confirmadas as trocas de parasitos entre espécies, segundo os dados da Fauna/JBRJ (Brasil 2018). Patogenias como a babesiose/erliquiose e cinomose são relevantes na região, oferecendo risco a diversas espécies nativas. Consideramos como real o risco de reemersão da raiva, devido à falta de cuidados vacinais e à presença de morcegos $e$ 
outras presas silvestres suscetíveis a essa patogenia próxima às residências, associando-se a isso o hábito de manter soltos os animais domésticos. Os problemas apresentados por este estudo poderiam ser amenizados por meio de campanhas de vacinação e consultas populares, assim como de uma campanha maciça de educação ambiental.

\section{Agradecimentos}

Agradecemos ao corpo de professores $e$ funcionários da Escola Nacional de Botânica Tropical, ao Jardim Botânico do Rio de Janeiro, especialmente às equipes da Fauna/JBRJ, Coordenação de Conservação de Área Verde e Diretoria de Ambiente e Tecnologia; aos moradores da Comunidade do Horto, que gentilmente responderam aos questionários, mesmo em tempos de tensão com as questões fundiárias; $e$ aos veterinários da região.

\section{Referências Bibliográficas}

Bergallo HG, Rocha, CFD, Alves MAS \& Van Sluys M. 2000. A Fauna Ameaçada do Estado do Rio de Janeiro. Editora UERJ. 166p.

Brasil. 2011. Quarto relatório nacional para a convenção sobre diversidade biológica. Ministério do Meio Ambiente. 248p.

Brasil. 2014(a). Leptospirose: diagnóstico e manejo clínico. Ministério da Saúde. 44p.

Brasil. 2014(b). Guia de Vigilância em Saúde. Ministério da Saúde. 812p.

Brasil. 2018. Jardim Botânico do Rio de Janeiro. Relatório do Trabalho Realizado Entre os Anos de 2013 a 2017 pelo Núcleo de Fauna do JBRJ. Rio de Janeiro: JBRJ. 18p.

Bussab WO \& Morettin PA. 2002. Estatística básica. São Paulo: Saraiva. 526p.

Canevari M \& Vaccaro. 2007. O Guia de mamíferos Del sur de America del Sur. LOLA. 424p.

Cheida CC, Nakano-Oliveira E, Fusco-Costa R, RochaMendes F \& Quadros J. 2006. Ordem Carnivora. In: Reis RN, Peracchi AL, Pedro WA, Lima IP. Mamíferos do Brasil. 2ed. Universidade Estadual de Londrina. 437p.

Chiarello AG, Aguiar LMS, Cerqueira R, Melo FR, Rodrigues FHG \& Silva VMF. 2008. Mamíferos Ameaçados de Extinção no Brasil. In: Machado ABM, Drummond GM, Paglia AP (eds.). Livro vermelho da fauna brasileira ameaçada de extinção. v. II. Fundação Biodiversitas. 471p.
Coimbra-Filho AF. 2000. Reintrodução do tucano-debico-preto (Ramphastos vitellinus ariel Vigors, 1826) no Parque Nacional da Tijuca (Rio de Janeiro - RJ) e notas sobre sua distribuição geográfica. Bol. Mus. Biol. Mello Leitão, 11/12: 189-200, 2000.

Costa LP, Leite YL, Mendes SL \& Ditchfield AD. Conservação de mamíferos no Brasil. Megadiversidade, 1(1): 103-112, 2005.

Dalmoro M \& Vieira KM. Dilemas na construção de escalas tipo Likert: o número de itens e a disposição influenciam nos resultados? Revista Organizacional, supl. Edição Especial Epistemologia e Métodos de Pesquisa, 6(3): 161-174, 2013.

Davidson WR, Nettles VF, Hayes LE, Howerth EW \& Couvillion CE. Diseases diagnosed in Gray foxes (Urocyon cinereoargentateus) from the southeastern United States. Journal of Wildlife Diseases, 28(1): 23-33, 1992.

De Angelo C, Paviolo A \& Di Blanco Y. 2008. Guia de huellas de los mamíferos de Misiones y otras áreas Del subtrópico de Argentina. Ediciones del Subtrópicos. 112p.

Dias VAC \& Ferreira FLA. Babesiose canina: Revisão. PubVet, 10(12): 886-888, 2016.

Emmons LH. 1997. Neotropical rainforest mammals: a Field guide. 2nd ed. The Chicago University Press. 307p.

Esbérard CEL. Diversidade de morcegos em área de Mata Atlântica regenerada no sudeste do Brasil. Rev. bras. Zoociências, 5(2): 189-204, 2003.

Fernandez FAZ, Ferreira GA, Nakano-Oliveira E, Andriolo A \& Genaro G. Spatial overlap between domestic cats and wild felines in an insular Atlantic Forest remnant. Animal Biology, 68(4): 157-172, 2018.

Fornazari F. \& Langoni H. Principais zoonoses em mamíferos silvestres. Veterinária e Zootecnia, 21(1): 10-24, 2014.

Freitas AM. 2012. Mamíferos do Nordeste brasileiro: espécies continentais. USEB. 131p.

Funk SM, Fiorello CV, Cleavelands S \& Gompper ME. 2001. The role of disease in carnivore ecology and conservation. In: Gittleman JL, Funk SM, Wayne BW \& MacDonald DW. Carnivore Conservation. Cambridge University Press. 690p.

Gordon JC \& Angrick EJ. Canine parvovirus: environmental effects on infectives. American Journal of Veterinary Research, 47: 1464-1467, 1986.

Greene CE \& Appel MJ. 1998. Canine Distemper. In: Greene CE (ed.). Infectious diseases of the dog and cat., 2ed. WB Saunders. 994p.

Heliodoro GC. 2014. Censo de Mastofauna Silvestre na Clínica de Animais Silvestres da Universidade Estácio de Sá, Vargem Pequena, Rio de Janeiro. Monografia (Especialização em Gestão de Biodiversidade). Escola de Botânica Tropical, do Instituto de Pesquisas Jardim Botânico do Rio de Janeiro. 89p. 
Hill M \& Hill A. 2005. Investigação por questionário. Edições Sílabo. 384p.

Horta MC, Pinter A, Cortez A, Soares RM, Gennari SM, Schumaker TTS \& Labruna MB. Rickettsia felis (Rickettsiales: Rickettsiaceae) in Ctenocephalides felis (Siphonaptera: Pulicidae) in the State of São Paulo, Brazil. Arquivo Brasileiro de Medicina Veterinária e Zootecnia, 57: 321-325, 2005.

Horta MC, Labruna MB, Pinter A, Linardi PM \& Schumaker TTS. Rickettsia infection in Five áreas of the state of São Paulo, Brazil. Memórias do Instituto Oswaldo Cruz, 102(7): 793-801, 2007.

Hughes J \& MacDonald DW. A review of the interactions between free-roaming domestic dogs and wildlife. Biological Conservation, 154: 341-351, 2013.

IPJB (Instituto de Pesquisa Jardim Botânico). 2003. Instituto Brasileiro de Administração Municipal. Plano diretor do Jardim Botânico do Rio de Janeiro. JBRJ, v.1, Janeiro.

Jones JPG, Asner GP, Butchart SHM \& Karanth KU. 2013. The 'why', 'what' and 'how' of monitoring for conservation. In: MacDonald DW \& Willis KJ. Key Topics in Conservation Biology 2. Wiley-Blackwell. 528p.

Jorge RSP. 2008. Caracterização do estado sanitário dos carnívoros silvestres da RPPN SESC Pantanal e de animais domésticos da região. Tese (Doutorado em Ciências) Faculdade de Medicina Veterinária, Universidade de São Paulo. 105p.

Kilgour RJ, Magle SB, Slater M, Christian A, Weiss E \& DiTullio M. Estimating free-roaming cat population sand the effects of one year Trap-NeuterReturn management effort in a highly urban area. UrbanEcosyst, 20: 207-216, 2017.

Krauze-Gryz D, Gryz JB, Goszczynski J, Chylarecki P \& Zmihorski M. Thegood, thebad, and the ugly: space use and intraguild interactions among three opportunistic predators - cat (Felis catus), dog (Canis lupus familiaris), and red fox (Vulpes vulpes) under human pressure. Canadian Journal of Zoology, 90(12): 1402-1413, 2012.

Lages SLS. 2009. Avaliação da população de cães e gatos com proprietário, e do nível de conhecimento sobre a Raiva e posse responsável em duas áreas contrastantes da cidade de Jaboticabal, São Paulo. Dissertação (mestrado em Medicina Veterinária) Universidade Estadual Paulista, Faculdade de Ciências Agrárias e Veterinárias. 76p.

Lagos AR, Belote DF, Borde LQ, Correa TFL \& Kutter KR. 2013. Guia dos mamíferos da área de influência da usina hidrelétrica de Batalha. FURNAS. 78p.

Leulmi H, Socolovschi C, Laudisoit A, Houemenou G \& Davoust B. Detection of Rickettsia felis, Rickettsia typhi, Bartonella Species and Yersinia pestis in Fleas (Siphonaptera) from Africa. PLOS Neglected Tropical Diseases, 8(10): 1-8, 2014.
Lindenmayer D \& Burgman M. 2005. Practical Conservation Biology. Csiro Publishing. 609p.

Magalhaes MN \& Lima ACP. 2008. Noções de probabilidade e estatística. EDUSP. 428p.

Marks BK \& Duncan RS. Use of Forest Edges by FreeRanging Cats and Dogs in an Urban Forest Fragment. Southeastern Naturalist, 8(3): 427-436, 2009.

Mendonça LET, Souto CM, Andrelino LL, Souto WMS, Washington WLS \& Alves RRN. Conflitos entre pessoas e animais silvestres no Semiárido paraibano $e$ suas implicações para conservação. Sitientibus, série Ciências Biológicas, 11(2): 185-199, 2011.

Miranda Filho A. Existe solução justa para o caso do Jardim Botânico do Rio de Janeiro? Revista Direito GV, 8(2): 485-526, 2012.

Mocellin GM, Simões TC, Nascimento TFS, Teixeira MLF, Lounibus LP \& Oliveira RL. Bromeliad-inhabiting mosquitoes in an urban botanical garden endemic Rio de Janeiro. Are bromeliasds productive habitats for the invasive vectors Aedes albopictus? Mem Inst Oswaldo Cruz, 104(8): 1171-1175, 2009.

Morell V. Serengeti's big cat going to the dogs. Science, 264(23): 1664, 1994.

Oliveira SN. 2017. Ectoparasitos hematófagos em mamíferos silvestres no Jardim Botânico do Rio de Janeiro. Monografia (Graduação em Ciências Biológicas) Faculdade de Ciências Biológicas, Universidade Veiga de Almeida. 37p.

Peixoto HC. 2012. Epidemiologia molecular de vírus da Raiva isolado de herbívoros e suínos procedentes da Amazônia Brasileira. Dissertação (Mestrado em Ciências). Faculdade de Medicina Veterinária e Zootécnica. Universidade de São Paulo. 92p.

Primack R \& Rodrigues E. Biologia da Conservação. Editora Planta, 2002. 327p.

Reed SE \& Merenlender AM. Effects of Management of Domestic Dogs and Recreation on Carnivores in Protected Areas in Northern California. Conservation Biology, 25(3): 1-10, 2010.

Reis NR, Fregonezi MN, Peracchi AL, Shibatta AO, Sartori ER, Rossaneis BK, Santos VR \& Ferracioli P. 2014. Mamíferos terrestres de médio e grande porte da Mata Atlântica. Technical Books Editora. 146p.

Rio de Janeiro. 2013. Resolução SES nº 674, de 12 de julho de 2013. Diário Oficial do Estado. <http:// www.rio.rj.gov.br/dlstatic/10112/4364979/4115670/ ResolucaoSESN674DE12.07.2013.pdf>. Acesso em: 24/06/2018.

Rio de Janeiro. 2015. Áreas Protegidas - Jardim Botânico - ano 2015. <http://www.rio.rj.gov.br/web/smac/ exibeconteudo?id=2367968 $>$. Acesso em: 12/06/2018. 
Rio de Janeiro. 2016a. Casos Confirmados de Quirópteros não Hematófagos no município do Rio de Janeiro. <http://www.rio.rj.gov.br/ igstatic/75/81/77/7581770.jpg >. http://www.rio.rj.gov. br/dlstatic/10112/7156849/4196689/AARgeral.pdf Acesso em: 21/07/2018.

Rio de Janeiro. 2016b. Lista Nacional de Notificação Compulsória (Portaria GM/MS n² 204 de 17 de fevereiro de 2016). <http://www.rio. rj.gov.br/dlstatic/10112/4364979/4155726/SVS NotifCompulsoria.pdf >.http://www.rio.rj.gov.br/ dlstatic/10112/7156849/4196690/AARmorcego.pdf Acesso em: 21/07/2018.

Rio de Janeiro. 2017. Casos Confirmados de Quirópteros não Hematófagos no município do Rio de Janeiro. <http://www.rio.rj.gov.br/ igstatic/75/81/77/7581774.jpg >. http://www.rio.rj.gov. br/dlstatic/10112/7156849/4196689/AARgeral.pdf Acesso em: 21/07/2018.

Rio de Janeiro. 2018a. Raiva. <http:/www.rio.rj.gov.br/ web/vigilanciasanitaria/raiva > . Acesso em: 21/07/2018.

Rio de Janeiro. 2018b. Casos Confirmados de Quirópteros não Hematófagos no município do Rio de Janeiro. <http://www.rio.rj.gov.br/ igstatic/78/82/04/7882043.jpg > . http://www.rio. rj.gov.br/dlstatic/10112/7156849/4196689/AARgeral. pdfAcesso em: 21/07/2018.

Rio de Janeiro. 2018c. Número de Atendimentos para realização da Profilaxia da Raiva Humana por Ano, Área Programática, Regiões Administrativas e Bairros de residência, município do Rio de Janeiro: 2007 a 2018. <http://www.rio.rj.gov.br/ dlstatic/10112/7156849/4243557/AARgeral.pdf $>$. Acesso em: 21/07/2018.

Rio de Janeiro. 2018d. Número de Agressões por Cães por Ano, Área Programática, Regiões Administrativas e Bairros de residência, Município do Rio de Janeiro: 2007 a 2018. <http://www.rio.rj.gov. br/dlstatic/10112/7156849/4196688/AARcaes.pdf $>$. Acesso em: 21/07/2018.
Rio de Janeiro. 2018e. Número de Agressões por Gatos por Ano, Área Programática, Regiões Administrativas e Bairros de residência, município do Rio de Janeiro: 2007 a 2018. <http://www.rio.rj.gov. br/dlstatic/10112/7156849/4196691/AARgatos.pdf > . Acesso em: 21/07/2018.

Rio de Janeiro. 2018f. Número de Agressões por Morcegos por Ano, Área Programática, Regiões Administrativas e Bairros de residência, município do Rio de Janeiro: 2007 a 2018. < http://www.rio.rj.gov.br/ dlstatic/10112/7156849/4196690/AARmorcego.pdf > . Acesso em: 21/07/2018.

Rio de Janeiro. 2018g. Número de Casos Confirmados de Leishmaniose Visceral Humana por Ano, Área Programática, Regiões Administrativas e Bairros, município do Rio de Janeiro: 2007 a 2018. < http:// www.rio.rj.gov.br/dlstatic/10112/7263738/4207415/ Leishmaniosevisceralcasos.pdf>. Acesso em: 21/07/2018.

Rio de Janeiro. 2018h. Número de Casos Confirmados de Leptospirose por Ano, Área Programática, Regiões Administrativas e Bairros, município do Rio de Janeiro: 2007 a 2018. <http://www.rio.rj.gov.br/ dlstatic/10112/7263723/4198851/Leptospirosecasos. pdf>. Acesso em: 21/07/2018.

Sigrist T. 2012. Mamíferos do Brasil. Avisbrasilis. 448p.

Silva IPM. Erliquiose canina: revisão de literatura. Revista Científica de Medicina Veterinária, 13(24): 1-15, 2015.

Trzyna T. 2014. Urban Protected Areas: Profiles and Best practice guidelines. Best Practice Protected Area Guidelines Series n ${ }^{\circ} 22$. IUCN: 2014. < https://portals. iucn.org/library/sites/library/files/documents/PAG-022. pdf $>$. Acesso em: 12/4/2018.

Vasconcellos SA. 2001. Zoonoses e saúde pública: riscos causados por animais exóticos. Biológico, 63(1/2): 63-65, 2001.

Wada MY, Rocha SM \& Maia-Elkhoury ANS. Situação da Raiva no Brasil, 2000 a 2009. Epidemiologia e Serviços de Saúde, 20(4): 509-518, 2011.

Biodiversidade Brasileira - BioBrasil.

Edição temática: Diálogos entre a Academia e a Gestão de Áreas Protegidas:

Programa de Pós-Graduação Profissional - Biodiversidade em Unidades de Conservação

$$
\text { n. 2, } 2020
$$

http://www.icmbio.gov.br/revistaeletronica/index.php/BioBR

Biodiversidade Brasileira é uma publicação eletrônica científica do Instituto Chico Mendes de

Conservação da Biodiversidade (ICMBio) que tem como objetivo fomentar a discussão e a disseminação de experiências em conservação e manejo, com foco em unidades de conservação $e$ espécies ameaçadas. 